\title{
Componentes genéticos aditivos e não aditivos em maracujazeiro-azedo
}

\author{
Carlos Eduardo Magalhães dos Santos ${ }^{(1)}$, Claudio Horst Bruckner ${ }^{(1)}$, Cosme Damião Cruz $^{(1)}$, \\ Dalmo Lopes de Siqueira ${ }^{(1)}$ e Luciana Domiciano Silva Rosado(1)
}

(1)Universidade Federal de Viçosa, Campus de Rio Paranaíba, Rodovia BR 354, Km 310, Caixa Postal 22, CEP 38810-000 Rio Paranaíba, MG. E-mail: carlos.magalhaes@ufv.br, bruckner@ufv.br, cdcruz@ufv.br, siqueira@ufv.br, luciana.rosado@ufv.br

Resumo - O objetivo deste trabalho foi avaliar os componentes genéticos aditivos e não aditivos em caracteres qualitativos e produtivos de maracujazeiro, para determinar a ocorrência de efeitos genéticos dominantes. Foram estudados 12 híbridos $\mathrm{F}_{1}$, obtidos entre duas populações distintas, com uso do delineamento II de Comstock e Robinson. Durante o primeiro e o segundo ano (safrinha e primeira safra, respectivamente), foram avaliados os seguintes caracteres: número de frutos por planta, produção estimada, massa de fruto, massa de casca, massa de polpa, comprimento longitudinal, diâmetro equatorial, espessura de casca, teor de sólidos solúveis totais, acidez titulável total e coloração da polpa. A produção do biênio 2004/2005 foi estimada a partir do número total de frutos, multiplicado pela massa média dos frutos. Foram observados efeitos de dominância e, portanto, de heterose, no primeiro ano, para massa de matéria fresca, massa de polpa, massa de casca e diâmetro equatorial do fruto e, no segundo ano, para diâmetro equatorial do fruto e coloração da polpa. Houve predominância dos efeitos aditivos para número de frutos e massa de fruto. Os valores de herdabilidade são indicativos de que a população avaliada pode ser utilizada para a formação da população-base, para promover seleção recorrente.

Termos para indexação: Passiflora edulis, genética quantitativa, heterose, produtividade, qualidade, seleção recorrente.

\section{Additive and nonadditive genetic components in passion fruit}

Abstract - The objective of this work was to assess the additive and nonadditive genetic components in passion fruit productive and qualitative traits, in order to determine the occurrence of dominant genetic effects. Twelve $\mathrm{F}_{1}$ hybrids, obtained from two different populations using design II of Comstock and Robinson, were studied. During the first and second years (off-season and first crop, respectively), the following traits were evaluated: number of fruits per plant, estimated yield, fruit mass, skin mass, pulp mass, longitudinal length, equatorial diameter, skin thickness, content of total soluble solids, total titratable acidity, and pulp color. The yield for the 2004/2005 biennium was estimated from the total number of fruit multiplied by the average fruit mass. Dominant effects and, therefore, heterosis were observed in the first year for fresh matter mass, pulp mass, skin mass, and fruit equatorial diameter, and, in the second year, for fruit equatorial diameter and pulp color. There was predominance of addictive effects for number of fruits and fruit mass. Heritability values are indicative that the evaluated population can be used to form a base population to promote recurrent selection.

Index terms: Passiflora edulis, quantitative genetics, heterosis, productivity, quality, recurrent selection.

\section{Introdução}

O maracujazeiro-azedo (Passiflora edulis Sims) é a principal espécie da família Passifloraceae cultivada no Brasil (Bruckner et al., 2002). O país se destaca como maior produtor mundial de maracujá, com 718.798 toneladas produzidas em 2009, com rendimento médio de $14,15 \mathrm{Mg} \mathrm{ha}^{-1}$ por ano (Instituto Brasileiro de Geografia e Estatística, 2010). No entanto, em pomares onde se aliam tecnologias de produção e a utilização de cultivares melhoradas geneticamente, a produtividade tem alcançado até $50 \mathrm{Mg} \mathrm{ha}^{-1}$ por ano (Meletti et al., 2005).

Nos programas de melhoramento do maracujazeiro, os principais aspectos estudados são o aumento da produtividade, a melhoria da qualidade dos frutos e a resistência às pragas e às doenças (Bruckner et al., 2002; Santos et al., 2008, 2009).

O maracujazeiro é uma planta alógama por excelência, reforçada pela autoincompatibilidade do tipo homomórfica e esporofítica (Bruckner et al., 1995), e, portanto, expressa elevada variabilidade 
genética. Essa alogamia favorece o emprego de vários métodos de melhoramento no aumento da frequência de alelos favoráveis ou a exploração do vigor híbrido ou da heterose (Bruckner et al., 2005). Contudo, para que essa variabilidade possa ser utilizada com maior eficiência, é necessário o conhecimento da composição genética dos genótipos que poderão ser cruzados, para otimizar a tomada de decisões na escolha das melhores combinações genéticas (Jung et al., 2007). A análise da capacidade de combinação tem sido utilizada, em inúmeros estudos, para descrever o valor genético de linhas parentais em relação ao seu potencial de produção de híbridos, e, também, para fornecer informações sobre a base genética da herança de um determinado carácter no melhoramento genético (Hegde et al., 2007; Krystkowiak et al., 2009).

A escolha de genitores somente a partir de caracteres desejáveis não assegura a obtenção de híbridos heteróticos e de progênies com elevada frequência de segregantes transgressivos. Consequentemente, qualquer progresso genético que ocorra em progênies provenientes de cruzamentos entre genitores escolhidos apenas com base no fenótipo poderá ser aleatório e de difícil repetibilidade (Jung et al., 2007).

Entre as metodologias empregadas na seleção de genitores em programas de melhoramento genético, estão os delineamentos genéticos de Comstock e Robinson e as análises dialélicas, as quais informam sobre o potencial dos genitores, quando em combinações híbridas, da ação gênica que controla os caracteres e da existência de heterose, o que proporciona grandes avanços na seleção (Ramalho et al., 1993; Cruz, 2005).

O delineamento genético II, proposto por Comstock \& Robinson (1948), baseia-se, de modo geral, na formação inicial de progênies de irmãos completos e meio-irmãos por intermédio da polinização controlada entre um grupo de genitores masculinos e um grupo de genitores femininos. Este delineamento é apropriado para a estimação dos componentes genéticos de variância nas populações de estudo e para as estimativas de parâmetros genéticos (Hallauer \& Miranda Filho, 1988).

Nos programas de melhoramento de plantas, estimativas de componentes de variância genética e do coeficiente de herdabilidade são importantes para subsidiar a escolha adequada da estratégia a ser empregada, além de possibilitar a obtenção de estimativas de ganhos com a seleção. Essas informações auxiliam na identificação de genótipos superiores, com base em valores fenotípicos (Aguiar, 2003).

Estudos sobre controle genético de caracteres associados ao melhoramento da cultura do maracujazeiro-azedo são escassos, assim como o emprego da metodologia de delineamento genético II.

O objetivo deste trabalho foi avaliar os componentes genéticos aditivos e não aditivos em caracteres produtivos e qualitativos de maracujazeiro, para determinar a ocorrência de efeitos genéticos dominantes.

\section{Material e Métodos}

O experimento foi conduzido no Laboratório de Análise de Frutos, do Departamento de Fitotecnia, da Universidade Federal de Viçosa, Viçosa, MG $\left(20^{\circ} 45^{\prime} \mathrm{S}\right.$ e $42^{\circ} 52^{\prime} \mathrm{W}$, a $648 \mathrm{~m}$ de altitude). O clima da região é do tipo Cwa, mesotérmico, conforme classificação de Köppen, com precipitação média anual de $1.200 \mathrm{~mm}$. Foram analisados 12 híbridos $F_{1}$, obtidos pela metodologia do delineamento genético II de Comstock \& Robinson (1948), tendo-se cruzado três pais com um grupo formado por quatro fêmeas. Os grupos de machos e de fêmeas foram constituídos de progênies selecionadas quanto à produtividade e à qualidade do fruto, em duas lavouras comerciais: uma no Município de Jacinto Machado, SC (28 $59^{\prime} \mathrm{S}$ e $49^{\circ} 45^{\prime} \mathrm{W}$, a $28 \mathrm{~m}$ de altitude), com clima do tipo Cfa, mesotérmico úmido da classificação de Köppen, e precipitação média anual de $1.250 \mathrm{~mm}$; e outra no Município de Guiricema, MG $\left(21^{\circ} 00^{\prime} \mathrm{S}\right.$ e $42^{\circ} 43^{\prime} \mathrm{W}$, a $261 \mathrm{~m}$ de altitude), com clima do tipo Cwa, mesotérmico da classificação de Köppen, e precipitação média anual de $1.564 \mathrm{~mm}$.

Os cruzamentos foram realizados manualmente de acordo com o procedimento descrito por Bruckner \& Otoni (1999). Dez flores do genitor feminino foram polinizadas com o pólen de cada genitor masculino. Sete dias após a realização dos cruzamentos, foi verificado o pegamento, e, aos 30 dias, foi colocada uma rede de náilon sobre os frutos, para evitar a sua queda e a consequente perda de sua identificação. Entre 65 a 90 dias após a realização dos cruzamentos, os frutos foram colhidos quando apresentavam mais de $30 \%$ da superfície de coloração amarelada, tendo-se retirado as suas sementes. 
As sementes foram colocadas para germinar em sacos de plásticos com $0,35 \mathrm{~L}$ de substrato comercial Plantmax HF (Eucatex, Paulínia, SP), tendo-se utilizado duas sementes por saco, e foram realizadas regas diárias. Quando as mudas começaram a emitir a primeira gavinha, em março de 2004, foram transferidas para o campo. Utilizou-se o delineamento experimental de blocos ao acaso, com três repetições e quatro plantas por parcela. O espaçamento utilizado foi de 3,5 $\mathrm{m}$ entre fileiras e 4,0 m entre plantas. A condução das plantas foi feita em espaldeira vertical, com 1,80 m de altura, em fio galvanizado $\mathrm{n}^{\mathrm{o}} 12$. Foram realizados todos os tratos culturais normalmente recomendados para a cultura.

$\mathrm{O}$ número de frutos por planta (NF) foi obtido pela contagem dos frutos durante o primeiro pico de produção do primeiro ano (dezembro de 2004). Para avaliação dos demais caracteres, foram colhidos dez frutos de cada planta, resultantes de polinização natural, com mais de $30 \%$ da coloração da casca amarelada. Foram determinados: massa média do fruto (MF), determinada pela pesagem de frutos, com balança digital modelo NC 5000 NW (Núcleo Equipamentos, Ltda., São Paulo, SP); massa média da casca (MC), obtida pela pesagem da casca de frutos; massa média da polpa (MP), calculada pela diferença entre a massa do fruto e a massa da casca $(\mathrm{MP}=\mathrm{MF}-\mathrm{MC})$; comprimento médio do fruto $(\mathrm{CF})$, determinado com paquímetro digital, série 799 modelo Universal (Starrett, Barueri, SP), tendo-se medido o eixo longitudinal do fruto; diâmetro médio do fruto (DF), obtido pela medição na região equatorial do fruto; espessura média da casca (EC), medida na porção mediana dos frutos cortados; teor médio de sólidos solúveis totais (SST), determinado por refratometria, tendo-se utilizado refratômetro digital portátil modelo PR-101 Pallet (Atago, Ribeirão Preto, SP), com leitura na faixa de $0^{\circ}$ a $32^{\circ}$ Brix, após a extração de uma alíquota do suco de cada fruto; acidez total titulável média (ATT), obtida com auxilio de bureta digital modelo Digitrate Pro $50 \mathrm{~mL}$ (Jencons Scientific LLC, Bridgeville, Pennsylvania, EUA), tendo-se expressado os resultados em grama equivalente de ácido cítrico por $100 \mathrm{~mL}$ de suco; e coloração da polpa (CP), determinada por escala com notas de 1 a 6 , em que a intensidade da cor variou do branco amarelado para o laranja, respectivamente, semelhante à utilizada por Linhales (2007).

Pesq. agropec. bras., Brasília, v.46, n.5, p.482-490, maio 2011
As avaliações foram realizadas com a produção colhida durante o primeiro e o segundo ano (safrinha e primeira safra, respectivamente), tendo-se analisado os dois anos. Foi feita a somatória do número de frutos dos dois anos, e a produção do biênio 2004/2005 foi estimada a partir do número total de frutos dos dois anos, multiplicado pela massa média dos frutos.

Foram realizadas análises de variância de cada um dos caracteres avaliados, com o programa Genes, de acordo com Cruz (2006). O modelo foi estabelecido com todos os efeitos aleatórios, conforme:

$$
\mathrm{Y}_{\mathrm{ijk}}=\mu+\mathrm{M}_{\mathrm{i}}+\mathrm{F}_{\mathrm{j}}+\mathrm{MF}_{\mathrm{ij}}+\mathrm{B}_{\mathrm{k}}+\varepsilon_{\mathrm{ijk}},
$$

em que: $Y_{\mathrm{ijk}}$ é a observação relativa ao cruzamento entre o macho i e fêmea $\mathrm{j}$; $\mu$ é a média geral; $\mathrm{M}_{\mathrm{i}}$ é o efeito relativo ao genitor masculino (macho) de ordem i; $F_{j}$ é o efeito relativo ao genitor feminino (fêmea) de ordem $\mathrm{j} ; \mathrm{MF}_{\mathrm{ij}}$ é o efeito da interação entre o genitor masculino (macho) de ordem i e o genitor feminino (fêmea) de ordem j; $B_{k}$ é o efeito da repetição de ordem $\mathrm{k}$; e $\varepsilon_{\mathrm{ijk}}$ é o erro experimental.

Para estimar os componentes de variância genotípica, variância genética aditiva $\left(\hat{\sigma}_{\mathrm{A}}^{2}\right)$ e variância genética por desvios de dominância $\left(\hat{\sigma}_{\mathrm{D}}^{2}\right)$, entre os indivíduos de uma população, os componentes de variância associados aos efeitos de natureza aleatória do modelo estatístico, de variância entre genitores masculinos $\left(\hat{\sigma}_{\mathrm{m}}^{2}\right)$ e entre genitores femininos $\left(\hat{\sigma}_{\mathrm{f}}^{2}\right)$, e de variância da interação entre genitores masculinos e femininos $\left(\hat{\sigma}_{\mathrm{mf}}^{2}\right)$ foram expressos em função de $\hat{\sigma}_{\mathrm{A}}^{2}$ e de $\sigma_{\mathrm{D}}^{2}$. As estimativas desses parâmetros foram obtidas a partir de equações que envolvem os quadrados médios da análise de variância.

As variâncias associadas aos efeitos de natureza aleatória do modelo estatístico, aos efeitos dos genitores masculinos e dos genitores femininos, e ao efeito da interação entre genitores masculinos e femininos foram estimadas por:

$\hat{\sigma}_{\mathrm{m}}^{2}=(\mathrm{QMM}-\mathrm{QMI}) / \mathrm{nf}, \quad \sigma_{\mathrm{f}}^{2}=(\mathrm{QMF}-\mathrm{QMI}) / \mathrm{nm}, \mathrm{e}$ $\sigma_{\mathrm{mf}}^{2}=(\mathrm{QMI}-\mathrm{QMR}) / \mathrm{n}$,

em que: QMM é o quadrado médio do efeito do genitor masculino; QMF é o quadrado médio do efeito do genitor feminino; QMI é o quadrado médio resultante da interação entre os genitores masculinos e femininos; QMR é o quadrado médio do resíduo; nf é o número de 
fêmeas; nm é o número de machos; e n é o número de blocos (repetições).

As expressões para o cálculo dos componentes de variância genética foram:

$$
\hat{\sigma}_{\mathrm{A}}^{2}=2\left(\hat{\sigma}_{\mathrm{m}}^{2}+\sigma_{\mathrm{f}}^{2}\right) \text { e } \sigma_{\mathrm{D}}^{2}=4 \sigma_{\mathrm{mf}}^{2} .
$$

Os componentes de variância genética são indicadores da variabilidade entre os indivíduos da população de referência. As variâncias genéticas entre médias de progênies também podem ser desdobradas em componentes atribuídos aos efeitos médios dos genes e aos desvios médios de dominância.

As herdabilidades foram calculadas pelas expressões:

$$
\mathrm{h}_{\mathrm{m}}^{2}=\hat{\sigma}_{\mathrm{m}}^{2} /(\mathrm{QMM} / \mathrm{nf}), \quad \mathrm{h}_{\mathrm{f}}^{2}=\hat{\sigma}_{\mathrm{f}}^{2} /(\mathrm{QMF} / \mathrm{nm}),
$$

e a herdabilidade dos indivíduos resultantes do cruzamento entre machos e por:

$$
\mathrm{h}_{\mathrm{mf}}^{2}=2\left(\hat{\sigma}_{\mathrm{m}}^{2}+\hat{\sigma}_{\mathrm{f}}^{2}\right) /\left(\hat{\sigma}_{\mathrm{m}}^{2}+\sigma_{\mathrm{f}}^{2}+\hat{\sigma}_{\mathrm{mf}}^{2}+\hat{\sigma}^{2}\right) .
$$

Os dados originais da coloração da polpa foram transformados para $(\mathrm{x}+0,5)^{0,5}$, tendo-se apresentado as médias originais.

\section{Resultados e Discussão}

Quando se promove o cruzamento entre genótipos contrastantes, espera-se que, em caso de heterose, a progênie resultante seja superior à média dos pais e que a análise de variância apresente significância para o valor do híbrido. Entretanto, não houve significância na análise dos híbridos avaliados para nenhum dos caracteres no primeiro e no segundo ano de produção, ou na produção do biênio 2004/2005 (Tabela 1), o que indica que não há diferenças nas composições gênicas das populações de maracujá utilizadas, já que, de acordo com Miranda Filho \& Vencovsky (1984), os maiores valores heteróticos estão associados à maior diversidade genética. De acordo com Vencovsky (1970), quando a heterose é significativa, a variância das frequências gênicas entre os genitores é suficientemente grande em pelo menos parte dos locos com dominância; os genitores, nessas condições, são divergentes para esses locos.
A heterose predita pela variância por efeitos de dominância, no primeiro ano de produção, ocorreu em relação à massa de matéria fresca, à massa da polpa, à massa da casca e ao diâmetro equatorial do fruto; os demais caracteres apresentaram valores negativos e não foi observado efeito de dominância (Tabela 2). No segundo ano de produção, somente o diâmetro equatorial do fruto e a coloração da polpa apresentaram variâncias positivas por efeitos de dominância.

A possível ocorrência de heterose para massa de matéria fresca do fruto e para massa da polpa e da casca, importantes para a produção de frutos maiores e mais valorizados, no primeiro ano de produção, pode ser explicada pela redução dos valores médios dessas massas do primeiro para o segundo ano, em decorrência do aumento no número de frutos e da maior partição de assimilados pelos frutos. Pimentel et al. (2008) relataram que o aumento da quantidade de frutos pode provocar redução progressiva em seu tamanho, em virtude da correlação negativa entre esses caracteres no maracujazeiro.

É de interesse a manifestação da heterose no primeiro ano, pois a produção elevada, neste ano, possibilita retorno mais rápido do capital investido, principalmente ao se considerar que a maior proporção desta produção abastece o mercado de fruta fresca, com preços que tendem a ser mais elevados do que os praticados pela indústria. Meletti et al. (2000) verificaram que, em determinadas épocas, frutos de melhor qualidade são remunerados a preços que podem ser até $150 \%$ superiores aos obtidos com a comercialização para indústria.

Não foi observada heterose no segundo ano e no conjunto da produção, provavelmente em decorrência do material genético estudado; portanto, é necessário aprofundar estudos para o melhoramento da população.

Moreira Júnior (1995) observou que, em milho, os altos valores heteróticos podem ser atribuídos ao fato de as populações, que originaram as linhagens formadoras do híbrido, estarem em processo de melhoramento, com altas frequências de alelos desejáveis, o que explica a substancial heterose proporcionada quando são cruzadas.

Programas de melhoramento genético de milho têm concentrado esforços nas combinações entre materiais mais divergentes e em processo de melhoramento, para obter materiais mais promissores e, consequentemente, 
diminuir os gastos e o tempo necessário para a realização de várias combinações híbridas, muitas vezes desnecessárias (Rinaldi et al., 2007).

Gonçalves et al. (2009) não observaram heterose para massa de matéria fresca do fruto em híbridos de maracujá avaliados com o delineamento I de Comstock \& Robinson (1948); contudo, verificaram efeito de dominância para número, comprimento longitudinal, diâmetro equatorial e espessura de casca dos frutos. Esses resultados diferem dos obtidos no presente estudo, em que apenas a espessura da casca apresentou efeito de heterose por desvios de dominância.

Ao se analisar o primeiro ano de produção, observouse que $\hat{\sigma}_{\text {mf }}^{2}$ apresentou valores negativos para número de frutos, comprimento longitudinal, espessura da casca, produção estimada, teor de sólidos solúveis, acidez total titulável e coloração da polpa. Assim, para esses caracteres, não houve $\sigma_{\mathrm{D}}^{2}$, ou seja, foram obtidas estimativas negativas, consideradas nulas. No segundo ano de produção, observaram-se valores

Tabela 1. Resumo da análise de variância dos caracteres do fruto em 12 famílias de maracujazeiro-azedo, avaliadas no delineamento genético II de Comstock e Robinson, no primeiro e segundo anos de produção e no biênio 2004/2005.

\begin{tabular}{|c|c|c|c|c|c|}
\hline \multirow[t]{2}{*}{ Carácter } & \multicolumn{4}{|c|}{ Quadrado médio } & \multirow[t]{2}{*}{ Média } \\
\hline & & & Primeiro ano & & \\
\hline Número de frutos por planta & $70,724^{\mathrm{ns}}$ & $16.271,728 * *$ & $1.786,837^{\mathrm{ns}}$ & $2.568,521$ & 56,38 \\
\hline Massa de matéria fresca do fruto $(\mathrm{g})$ & $1.287,186^{\mathrm{ns}}$ & $1.321,273^{\mathrm{ns}}$ & $1.088,954^{\mathrm{ns}}$ & 728,444 & 217,04 \\
\hline Massa de matéria fresca da polpa $(\mathrm{g})$ & $593,027^{\mathrm{ns}}$ & $149,447^{\mathrm{ns}}$ & $381,652^{\text {ns }}$ & 285,599 & 98,83 \\
\hline Massa de matéria fresca da casca $(\mathrm{g})$ & $176,587^{\mathrm{ns}}$ & $616,332^{\text {ns }}$ & $278,605^{\text {ns }}$ & 140,965 & 118,78 \\
\hline Comprimento longitudinal (mm) & $74,620 * *$ & $273,197 * *$ & $4,207^{\mathrm{ns}}$ & 14,967 & 91,25 \\
\hline Diâmetro equatorial (mm) & $8,909^{\text {ns }}$ & $35,086^{\mathrm{ns}}$ & $13,678^{\text {ns }}$ & 8,714 & 78,71 \\
\hline Espessura da casca (mm) & $0,154^{\mathrm{ns}}$ & $0,148^{\mathrm{ns}}$ & $0,320^{\text {ns }}$ & 0,323 & 4,81 \\
\hline Produção estimada (kg por planta) & $31,426^{\mathrm{ns}}$ & $271,964 * *$ & $15,431^{\mathrm{ns}}$ & 45,602 & 11,41 \\
\hline Teor de sólidos solúveis totais ( ${ }^{\circ}$ Brix) & $0,325^{\mathrm{ns}}$ & $10,456^{* *}$ & $0,783^{\text {ns }}$ & 0,926 & 13,92 \\
\hline Acidez total titulável ${ }^{(1)}$ & $0,196^{\mathrm{ns}}$ & $0,365^{*}$ & $0,056^{\mathrm{ns}}$ & 0,177 & 2,91 \\
\hline \multirow[t]{2}{*}{$\underline{\text { Coloração da polpa }}$} & $0,004^{\mathrm{ns}}$ & $0,007^{\mathrm{ns}}$ & $0,003^{\mathrm{ns}}$ & 0,006 & 4,62 \\
\hline & \multicolumn{5}{|c|}{ Segundo ano } \\
\hline Número de frutos por planta & $615,224 \mathrm{~ns}$ & $2.847,595 \mathrm{~ns}$ & $729,881 \mathrm{~ns}$ & $1.011,476$ & 85,93 \\
\hline Massa de matéria fresca do fruto $(\mathrm{g})$ & $1.437,304 *$ & $7.217,223 * *$ & $210,364 \mathrm{~ns}$ & 814,974 & 199,04 \\
\hline Massa de matéria fresca da polpa (g) & $645,692 * *$ & $2.386,328 * *$ & $61,014 \mathrm{~ns}$ & 270,764 & 86,20 \\
\hline Massa de matéria fresca da casca $(\mathrm{g})$ & $205,122 \mathrm{~ns}$ & $1.658,663^{* *}$ & $85,332 \mathrm{~ns}$ & 197,032 & 112,75 \\
\hline Comprimento longitudinal (mm) & $82,175 \mathrm{~ns}$ & $473,944 * *$ & $37,161 \mathrm{~ns}$ & 48,079 & 87,83 \\
\hline Diâmetro equatorial (mm) & $61,267 \mathrm{~ns}$ & $111,453 \mathrm{~ns}$ & $27,221 \mathrm{~ns}$ & 25,451 & 77,13 \\
\hline Espessura da casca (mm) & $0,856 \mathrm{~ns}$ & $0,446 \mathrm{~ns}$ & $0,655 \mathrm{~ns}$ & 0,705 & 4,41 \\
\hline Produção estimada (kg por planta) & $37,701 \mathrm{~ns}$ & $185,970 *$ & $35,206 \mathrm{~ns}$ & 54,533 & 18,00 \\
\hline Teor de sólidos solúveis totais ( $\left.{ }^{\circ} \mathrm{Brix}\right)$ & $6,608 \mathrm{~ns}$ & $1,219 \mathrm{~ns}$ & $2,008 \mathrm{~ns}$ & 2,388 & 14,58 \\
\hline Acidez total titulável ${ }^{(1)}$ & $0,075 \mathrm{~ns}$ & $0,113 \mathrm{~ns}$ & $0,109 \mathrm{~ns}$ & 0,132 & 3,72 \\
\hline \multirow[t]{2}{*}{ Coloração da polpa } & $0,047 \mathrm{~ns}$ & 0,090ns & $0,060 \mathrm{~ns}$ & 0,058 & 4,50 \\
\hline & \multicolumn{5}{|c|}{ Biênio 2004/2005 } \\
\hline Número de frutos por planta & $70,724 \mathrm{~ns}$ & $16.271,728 * *$ & $1.786,837 \mathrm{~ns}$ & $2.568,521$ & 142,31 \\
\hline Massa de matéria fresca do fruto $(\mathrm{g})$ & $1.240,669 \mathrm{~ns}$ & $3.422,607 * *$ & $310,947 \mathrm{~ns}$ & 456,044 & 208,04 \\
\hline Massa de matéria fresca da polpa (g) & $613,930 *$ & $880,986 * *$ & $111,070 \mathrm{~ns}$ & 173,370 & 92,52 \\
\hline Massa de matéria fresca da casca $(\mathrm{g})$ & $123,416 \mathrm{~ns}$ & $1.050,534 * *$ & $67,814 \mathrm{~ns}$ & 91,541 & 115,76 \\
\hline Comprimento longitudinal (mm) & $71,326^{*}$ & $362,218 * *$ & $10,669 \mathrm{~ns}$ & 21,300 & 89,54 \\
\hline Diâmetro equatorial (mm) & $27,747 \mathrm{~ns}$ & $57,589 *$ & $8,037 \mathrm{~ns}$ & 9,711 & 77,92 \\
\hline Espessura da casca (mm) & $0,144 \mathrm{~ns}$ & $0,243 \mathrm{~ns}$ & $0,264 \mathrm{~ns}$ & 0,242 & 4,61 \\
\hline Produção estimada (kg por planta) & $10,697 \mathrm{~ns}$ & $894,466^{* *}$ & $79,580 \mathrm{~ns}$ & 122,533 & 29,41 \\
\hline Teor de sólidos solúveis totais ( ${ }^{\circ}$ Brix) & $1,278 \mathrm{~ns}$ & $3,773 * *$ & $0,347 \mathrm{~ns}$ & 0,895 & 14,25 \\
\hline Acidez total titulável ${ }^{(1)}$ & $0,127^{*}$ & $0,062 \mathrm{~ns}$ & $0,018 \mathrm{~ns}$ & 0,085 & 3,32 \\
\hline Coloração da polpa & $0,008 \mathrm{~ns}$ & $0,034 \mathrm{~ns}$ & $0,013 \mathrm{~ns}$ & 0,018 & 4,56 \\
\hline
\end{tabular}

(1)Percentagem de ácido cítrico, em grama equivalente de ácido cítrico por $100 \mathrm{~mL}$ de suco. QMM, quadrado médio do efeito do genitor masculino; QMF, quadrado médio do efeito do genitor feminino; QMI, quadrado médio resultante da interação entre os genitores masculinos e femininos; QMR, quadrado

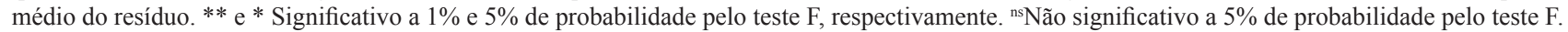


negativos para os caracteres avaliados, exceto para diâmetro equatorial do fruto e coloração da polpa. Ao se considerar os dois anos em conjunto, foram obtidos valores negativos para todos os caracteres, exceto para espessura da casca.

As variâncias obtidas para o genitor masculino $\left(\hat{\sigma}_{\mathrm{m}}^{2}\right)$ e para o genitor feminino $\left(\hat{\sigma}_{\mathrm{f}}^{2}\right)$ foram utilizadas na obtenção das demais variâncias.

No primeiro ano, o carácter com maior destaque para $\left(\hat{\sigma}_{\mathrm{A}}^{2}\right)$ foi o número de frutos, seguido de massa do fruto. No segundo ano, destacaram-se as massas do fruto e da polpa e o número de frutos. Na produção do biênio 2004/2005, o número de frutos e a massa dos frutos apresentaram valores expressivos quanto à variância aditiva. Os efeitos aditivos mostraram ser preponderantes no controle genético desses caracteres. Contudo, a espessura da casca, o teor de sólidos solúveis, a acidez titulável e a coloração da polpa apresentaram valores baixos ou nulos, o que indica a dificuldade de progresso genético para esses caracteres

Tabela 2. Estimativa de componentes de variância dos caracteres do fruto em 12 famílias de maracujazeiro-azedo avaliadas no delineamento genético II de Comstock e Robinson, no primeiro e segundo anos de produção e no biênio 2004/2005.

\begin{tabular}{|c|c|c|c|c|c|}
\hline \multirow[t]{2}{*}{ Carácter } & \multicolumn{5}{|c|}{ Componente de variância $^{(1)}$} \\
\hline & $\hat{\sigma}_{\mathrm{m}}^{2}$ & $\hat{\sigma}_{f}^{2}$ & $\hat{\sigma}_{\mathrm{mf}}^{2}$ & $\hat{\sigma}_{\mathrm{A}}^{2}$ & $\hat{\sigma}_{\mathrm{D}}^{2}$ \\
\hline & \multicolumn{5}{|c|}{ Primeiro ano } \\
\hline Número de frutos por planta & 20,583 & 554,584 & -184.574 & $1.150,336$ & $-738,296$ \\
\hline Massa de matéria fresca do fruto $(\mathrm{g})$ & 16,519 & 25,809 & 120,170 & 84,657 & 480,679 \\
\hline Massa de matéria fresca da polpa (g) & 17,614 & $-25,800$ & 32,018 & $-16,372$ & 128,071 \\
\hline Massa de matéria fresca da casca $(\mathrm{g})$ & $-8,501$ & 37,525 & 45,880 & 58,047 & 183,520 \\
\hline Comprimento longitudinal (mm) & 5,867 & 29,887 & $-3,589$ & 71,511 & $-14,359$ \\
\hline Diâmetro equatorial (mm) & $-0,397$ & 2,378 & 1,654 & 3,962 & 6,619 \\
\hline Espessura da casca (mm) & $-0,013$ & $-0,019$ & $-0,001$ & $-0,065$ & $-0,004$ \\
\hline Produção estimada (kg por planta) & 1,332 & 28,503 & $-10,056$ & 59,672 & $-40,227$ \\
\hline Teor de sólidos solúveis totais $\left({ }^{\circ} \mathrm{Brix}\right)$ & $-0,038$ & 1,074 & $-0,047$ & 2,073 & $-0,190$ \\
\hline Acidez total titulável ${ }^{(2)}$ & 0,011 & 0,034 & $-0,040$ & 0,092 & $-0,160$ \\
\hline \multirow[t]{2}{*}{ Coloração da polpa } & 0,000 & 0,000 & $-0,000$ & 0,001 & $-0,003$ \\
\hline & \multicolumn{5}{|c|}{ Segundo ano } \\
\hline Número de frutos por planta & $-9,554$ & 235,301 & -93.864 & 451,493 & $-375,458$ \\
\hline Massa de matéria fresca do fruto $(\mathrm{g})$ & 102,245 & 778,539 & $-201,536$ & 1761,569 & $-806,145$ \\
\hline Massa de matéria fresca da polpa (g) & 48,723 & 258,368 & $-69,916$ & 614,182 & $-279,667$ \\
\hline Massa de matéria fresca da casca $(\mathrm{g})$ & 9,982 & 174,814 & $-37,233$ & 369,594 & $-148,933$ \\
\hline Comprimento longitudinal (mm) & 3,751 & 48,531 & $-3,639$ & 104,565 & $-14,557$ \\
\hline Diâmetro equatorial (mm) & 2,837 & 9,359 & 0,590 & 24,392 & 2,359 \\
\hline Espessura da casca (mm) & 0,016 & $-0,023$ & $-0,016$ & $-0,012$ & $-0,066$ \\
\hline Produção estimada (kg por planta) & 0,207 & 16,751 & $-6,442$ & 33,918 & $-25,768$ \\
\hline Teor de sólidos solúveis totais $\left({ }^{\circ} \mathrm{Brix}\right)$ & 0,383 & $-0,087$ & $-0,126$ & 0,591 & $-0,505$ \\
\hline Acidez total titulável ${ }^{(2)}$ & $-0,002$ & 0,000 & $-0,007$ & $-0,005$ & $-0,030$ \\
\hline \multirow[t]{2}{*}{ Coloração da polpa } & $-0,001$ & 0,003 & 0,000 & 0,004 & 0,002 \\
\hline & \multicolumn{5}{|c|}{ Biênio 2004/2005 } \\
\hline Número de frutos por planta & $-143,009$ & $1.609,423$ & $-260,561$ & $2.932,845$ & $-1.042,245$ \\
\hline Massa de matéria fresca do fruto $(\mathrm{g})$ & 77,476 & 345,739 & $-48,365$ & 846,433 & $-193,462$ \\
\hline Massa de matéria fresca da polpa $(\mathrm{g})$ & 41,905 & 85,562 & $-20,766$ & 254,902 & $-83,065$ \\
\hline Massa de matéria fresca da casca (g) & 4,633 & 109,191 & $-7,909$ & 227,649 & $-31,636$ \\
\hline Comprimento longitudinal (mm) & 5,054 & 39,061 & $-3,543$ & 88,231 & $-14,175$ \\
\hline Diâmetro equatorial (mm) & 1,642 & 5,505 & $-0,557$ & 14,296 & $-2,231$ \\
\hline Espessura da casca $(\mathrm{mm})$ & $-0,010$ & $-0,002$ & 0,007 & $-0,024$ & 0,029 \\
\hline Produção estimada (kg por planta) & $-5,740$ & 90,542 & $-14,317$ & 169,605 & $-57,270$ \\
\hline Teor de sólidos solúveis totais $\left({ }^{\circ} \mathrm{Brix}\right)$ & 0,077 & 0,380 & $-0,182$ & 0,916 & $-0,730$ \\
\hline Acidez total titulável ${ }^{(2)}$ & 0,009 & 0,004 & $-0,022$ & 0,028 & $-0,088$ \\
\hline Coloração da polpa & $-0,000$ & 0,002 & $-0,001$ & 0,003 & $-0,006$ \\
\hline
\end{tabular}

${ }^{(1)} \hat{\sigma}_{\mathrm{m}}^{2}, \hat{\sigma}_{\mathrm{f}}^{2}$ e $\hat{\sigma}_{\mathrm{mf}}^{2}$, componentes de variância associados ao efeito dos genitores masculinos, ao efeito dos genitores femininos e ao efeito da interação entre genitores masculinos e femininos, respectivamente; $\hat{\sigma}_{\mathrm{A}}^{2}$, componente de variância genético aditivo; e $\hat{\sigma}_{\mathrm{D}}^{2}$, componente de variância dos efeitos de dominância. Valores negativos devem ser considerados como estimativas do valor real zero. ${ }^{(2)}$ Percentagem de ácido cítrico, em grama equivalente de ácido cítrico por $100 \mathrm{~mL}$ de suco. 
quando a população é submetida a sucessivos ciclos de seleção.

A falta de heterose predita pela variância atribuída aos desvios de dominância nos diversos caracteres pode ser visualizada como falta de complementariedade entre os alelos dos genitores, sendo necessário submeter essa população à seleção recorrente.

Os valores dos coeficientes de herdabilidade mais elevados foram obtidos para comprimento do fruto, no primeiro ano de produção (Tabela 3). Entretanto, no segundo ano, o carácter que apresentou os maiores valores foi a massa da polpa do fruto. O comprimento do fruto apresentou coeficientes de herdabilidade elevados no primeiro e no segundo ano de produção, o que indica que melhorias, nesse carácter, podem ser alcançadas em ciclos de seleção futuros.

No geral, os maiores coeficientes de herdabilidade no primeiro e no segundo ano de produção foram obtidos para as fêmeas $\left(\mathrm{h}_{\mathrm{f}}^{2}\right)$, em comparação aos genitores masculinos $\left(\mathrm{h}_{\mathrm{m}}^{2}\right)$. Um padrão semelhante foi observado na produção do biênio 2004/2005. Gonçalves et al. (2007) observaram elevados coeficientes de

Tabela 3. Coeficientes de herdabilidade, no sentido restrito, relativos aos caracteres do fruto em 12 famílias de maracujazeiroazedo avaliadas no delineamento II de Comstock e Robinson, no primeiro e segundo anos de produção e no biênio $2004 / 2005$.

\begin{tabular}{|c|c|c|c|c|}
\hline \multirow[t]{2}{*}{ Carácter } & \multicolumn{4}{|c|}{ Coeficientes de herdabilidade $(\%)^{(1)}$} \\
\hline & $\mathrm{h}_{\mathrm{m}}^{2}$ & $\mathrm{~h}_{\mathrm{f}}^{2}$ & $\mathrm{~h}_{\mathrm{mf}}^{2}$ & $\mathrm{~h}_{\mathrm{i}}^{2}$ \\
\hline & \multicolumn{4}{|c|}{ Primeiro ano } \\
\hline Número de frutos por planta & 31,71 & 90,37 & 64,21 & 77,92 \\
\hline Massa de matéria fresca do fruto $(\mathrm{g})$ & 15,40 & 17,58 & 9,70 & 9,50 \\
\hline Massa de matéria fresca da polpa (g) & 35,64 & $-155,38$ & $-7,95$ & $-5,29$ \\
\hline Massa de matéria fresca da casca $(\mathrm{g})$ & $-57,77$ & 54,80 & 25,40 & 26,89 \\
\hline Comprimento longitudinal (mm) & 94,36 & 98,46 & 90,44 & 151,69 \\
\hline Diâmetro equatorial (mm) & $-53,54$ & 61,01 & 30,32 & 32,08 \\
\hline Espessura da casca (mm) & $-108,04$ & $-115,76$ & $-31,51$ & $-22,76$ \\
\hline Produção estimada (kg por planta) & 50,90 & 94,33 & 71,43 & 91,27 \\
\hline Teor de sólidos solúveis totais $\left({ }^{\circ}\right.$ Brix) & $-140,85$ & 92,51 & 75,08 & 108,26 \\
\hline Acidez total titulável (2) & 71,30 & 84,55 & 49,67 & 50,35 \\
\hline \multirow[t]{2}{*}{ Coloração da polpa } & 21,81 & 52,32 & 20,52 & 17,42 \\
\hline & \multicolumn{4}{|c|}{ Segundo ano } \\
\hline Número de frutos por planta & $-18,64$ & 74,37 & 39,35 & 39,49 \\
\hline Massa de matéria fresca do fruto $(\mathrm{g})$ & 85,36 & 97,09 & 81,48 & 117,89 \\
\hline Massa de matéria fresca da polpa $(\mathrm{g})$ & 90,55 & 97,44 & 82,57 & 120,92 \\
\hline Massa de matéria fresca da casca $(\mathrm{g})$ & 58,40 & 94,86 & 76,81 & 107,25 \\
\hline Comprimento longitudinal (mm) & 54,78 & 92,16 & 75,14 & 108,11 \\
\hline Diâmetro equatorial (mm) & 55,57 & 75,58 & 52,47 & 63,79 \\
\hline Espessura da casca (mm) & 23,51 & $-46,73$ & $-03,09$ & $-01,88$ \\
\hline Produção estimada (kg por planta) & 06,62 & 81,07 & 48,59 & 52,14 \\
\hline Teor de sólidos solúveis totais ( ${ }^{\circ}$ Brix) & 69,61 & $-64,77$ & 22,16 & 23,12 \\
\hline Acidez total titulável ${ }^{(2)}$ & $-45,50$ & 02,83 & $-04,68$ & $-04,10$ \\
\hline \multirow[t]{2}{*}{ Coloração da polpa } & $-25,54$ & 33,73 & 9,36 & 7,78 \\
\hline & \multicolumn{4}{|c|}{ Biênio 2004/2005 } \\
\hline Número de frutos por planta & $-2.426,47$ & 89,02 & 62,94 & 77,70 \\
\hline Massa de matéria fresca do fruto $(\mathrm{g})$ & 74,94 & 90,91 & 72,97 & 101,87 \\
\hline Massa de matéria fresca da polpa (g) & 81,91 & 87,39 & 68,38 & 91,02 \\
\hline Massa de matéria fresca da casca $(\mathrm{g})$ & 45,05 & 93,54 & 77,97 & 115,29 \\
\hline Comprimento longitudinal (mm) & 85,04 & 97,05 & 87,34 & 142,60 \\
\hline Diâmetro equatorial (mm) & 71,03 & 86,04 & 66,02 & 87,70 \\
\hline Espessura da casca (mm) & $-82,64$ & $-08,48$ & $-12,07$ & $-10,33$ \\
\hline Produção estimada (kg por planta) & $-643,91$ & 91,10 & 67,91 & 87,87 \\
\hline Teor de sólidos solúveis totais ( ${ }^{\circ}$ Brix) & 72,82 & 90,79 & 64,91 & 78,25 \\
\hline Acidez total titulável ${ }^{(2)}$ & 85,54 & 70,69 & 39,59 & 36,46 \\
\hline Coloração da polpa & $-62,50$ & 61,36 & 23,58 & 20,57 \\
\hline
\end{tabular}

${ }^{(1)} h_{\mathrm{m}}^{2}, \mathrm{~h}_{\mathrm{f}}^{2}, \mathrm{~h}_{\mathrm{mf}}^{2}$ e $\mathrm{h}_{\mathrm{i}}^{2}$, herdabilidades de macho e fêmea, resultante do cruzamento entre macho e fêmea, e de indivíduo, respectivamente. Valores negativos das herdabilidades devem ser considerados como estimativa nula. ${ }^{(2)}$ Percentagem de ácido cítrico, em grama equivalente de ácido cítrico por $100 \mathrm{~mL}$ de suco. 
herdabilidade em famílias de machos, ao utilizar o delineamento genético I de Comstock e Robinson em 113 famílias de maracujazeiro.

As herdabilidades referentes aos indivíduos $\left(\mathrm{h}_{\mathrm{i}}^{2}\right)$ apresentaram valores de alta magnitude para todos os caracteres, na produção do biênio 2004/2005, exceto para espessura da casca, acidez titulável e coloração da polpa. Como os ganhos de seleção preditos dependem da herdabilidade apresentada pelo carácter estudado, presume-se a ocorrência de baixos percentuais de ganho de seleção, nesses caracteres, ao longo dos ciclos de seleção.

\section{Conclusões}

1. Há efeito de dominância e, portanto, de heterose, no primeiro ano de produção, para as características massa de matéria fresca, massa da polpa, massa da casca e diâmetro equatorial do fruto.

2. No segundo ano de produção, somente o diâmetro equatorial do fruto e a coloração da casca apresentam variâncias, em virtude dos efeitos de dominância não nula.

3. Há predominância dos efeitos aditivos para número de frutos e massa do fruto.

4. Os valores de herdabilidade obtidos são indicativos de que a população avaliada pode ser utilizada para a formação da população-base, para promover seleção recorrente.

\section{Agradecimentos}

Ao Conselho Nacional de Desenvolvimento Científico e Tecnológico e à Fundação de Amparo à Pesquisa do Estado de Minas Gerais, pelo apoio financeiro.

\section{Referências}

AGUIAR, A.M. Uso do delineamento III com marcadores moleculares para a análise genética da produção de grãos e seus componentes em milho. 2003. 127p. Tese (Doutorado) Escola Superior de Agricultura Luiz de Queiroz, Piracicaba.

BRUCKNER, C.H.; CASALI, V.W.D.; MORAES, C.F. de; REGAZZI, A.J.; SILVA, E.A.M. da. Self-incompatibility in passion fruit (Passiflora edulis Sims). Acta Horticulturae, v.370, p.45-57, 1995.

BRUCKNER, C.H.; MELETTI, L.M.M.; OTONI, W.C.; ZERBINI JÚNIOR, F.M. Maracujazeiro. In: BRUCKNER, C.H. (Ed.). Melhoramento de fruteiras tropicais. Viçosa: UFV, 2002. p.373-409.
BRUCKNER, C.H.; OTONI, W.C. Hibridação em maracujá. In: BORÉM, A. (Ed.). Hibridação artificial de plantas. Viçosa: UFV, 1999. p.379-399.

BRUCKNER, C.H.; SUASSUNA, T. de M.F.; RÊGO, M.M.; NUNES, E.S. Auto-incompatibilidade do maracujá-implicações no melhoramento genético. In: FALEIRO, F.G.; JUNQUEIRA, N.T.V.; BRAGA, M.F. (Ed.). Maracujá: germoplasma e melhoramento genético. Planaltina: Embrapa Cerrados, 2005. p.315-338.

COMSTOCK, R.E.; ROBINSON, H.F. The components of genetic variance in populations of biparental progenies and their use in estimating the average degree of dominance. Biometrics, v.4, p.254-266, 1948.

CRUZ, C.D. Princípios de genética quantitativa. Viçosa: UFV, 2005. 394p.

CRUZ, C.D. Programa Genes: biometria. Viçosa: UFV, 2006. $382 \mathrm{p}$.

GONÇALVES, G.M.; VIANA, A.P.; BEZERRA NETO, F.V.; PEREIRA, M.G.; PEREIRA, T.N.S. Seleção e herdabilidade na predição de ganhos genéticos em maracujá-amarelo. Pesquisa Agropecuária Brasileira, v.42, p.193-198, 2007.

GONÇALVES, G.M.; VIANA, A.P.; PEREIRA, M.G.; BEZERRA NETO, F.V.; AMARAL JÚNIOR, A.T. do; PEREIRA, T.N.S.; GONÇALVES, T.J.M. Genetic parameter estimates in yellow passion fruit based on Design I. Brazilian Archives of Biology And Technology, v.52, p.523-530, 2009.

HALLAUER, A.R.; MIRANDA FILHO, J.B. Quantitative genetics in maize breeding. Ames: Iowa State University Press, 1988. 468p.

HEGDE, V.S.; YADAV, S.S.; KUMAR, J. Heterosis and combining ability for biomass and harvest index in chickpea under a drought-prone, short-duration environment. Euphytica, v.157, p.223-230, 2007.

INSTITUTO BRASILEIRO DE GEOGRAFIA E ESTATÍSTICA. Indicadores: produção agrícola municipal. Disponível em: $<$ http:// www.ibge.gov.br/>. Acesso em: 05 nov. 2010.

JUNG, M.S.; VIEIRA, E.A.; SILVA, G.O. da; BRANCKER, A.; NODARI, R.O. Capacidade de combinação por meio de análise multivariada para caracteres fenotípicos em maracujazeiro-doce. Pesquisa Agropecuária Brasileira, v.42, p.689-694, 2007.

KRYSTKOWIAK, K.; ADAMSKI, T.; SURMA, M.; KACZMAREK, Z. Relationship between phenotypic and genetic diversity of parental genotypes and the specific combining ability and heterosis effects in wheat (Triticum aestivum L.). Euphytica, v.165, p.419-434, 2009.

LINHALES, H. Seleção em famílias de irmãos completos de maracujazeiro amarelo (Passiflora edulis Sims f. flavicarpa Deg.) no segundo ano de produção. 2007. 72p. Tese (Mestrado) Universidade Federal de Viçosa, Viçosa.

MELETTI, L.M.M.; SANTOS, R.R. dos; MINAMI, K. Melhoramento do maracujazeiro-amarelo: obtenção do cultivar 'Composto IAC-27'. Scientia Agricola, v.57, p.491-498, 2000.

MELETTI, L.M.M.; SCOTT, M.D.S.; BERNACCI, L.C.; PASSOS, I.R.S. Melhoramento genético do maracujá: passado e futuro. 
In: FALEIRO, F.G.; JUNQUEIRA, N.T.V.; BRAGA, M.F. (Ed.). Maracujá: germoplasma e melhoramento genético. Planaltina: Embrapa Cerrados, 2005. p.55-78.

MIRANDA FILHO, J.B. de; VENCOVSKY, R. Analysis of diallel crosses among open-pollinated varieties of maize (Zea mays L.). Maydica, v.29, p.217-234, 1984.

MOREIRA JÚNIOR, W.N. Componentes de heterose a partir de testadores recíprocos intergrupos em linhagens de milho (Zea mays L.). 1995. 114p. Dissertação (Mestrado) - Universidade Federal de Goiás, Goiânia.

PIMENTEL,L.D.; STENZEL, N.M.C.; CRUZ, C.D.; BRUCKNER, C.H. Seleção precoce de maracujazeiro pelo uso da correlação entre dados de produção mensal e anual. Pesquisa Agropecuária Brasileira, v.43, p.1303-1309, 2008.

RAMALHO, M.A.P.; SANTOS, J.B. dos; ZIMERMANN, M.J. de $O$. Genética quantitativa em plantas autógamas: aplicações ao melhoramento do feijoeiro. Goiânia: UFG, 1993. 271p.
RINALDI, D.A.; PÍPOLO, V.C.; GERAGE, A.C.; RUAS, C. de F.; FONSECA JÚNIOR, N. da S.; SOUZA, A. de; SOUZA, S.G.H. de; GARBUGLIO, D.D. Correlação entre heterose e divergência genética estimadas por cruzamentos dialélicos e marcadores moleculares RAPD em populações de milho-pipoca. Bragantia, v.66, p.183-192, 2007.

SANTOS, C.E.M. dos; BRUCKNER, C.H.; CRUZ, C.D.; SIQUEIRA, D.L. de; PIMENTEL, L.D. Características físicas do maracujá-azedo em função do genótipo e massa do fruto. Revista Brasileira de Fruticultura, v.3, p.1102-1110, 2009.

SANTOS, C.E.M. dos; PISSIONI, L.L.M.; MORGADO, M.A.D.; CRUZ, C.D.; BRUCKNER, C.H. Estratégias de seleção em progênies de maracujazeiro-amarelo quanto ao vigor e incidência de verrugose. Revista Brasileira de Fruticultura, v.30, p.444-449, 2008 .

VENCOVSKY, R. Alguns aspectos teóricos e aplicados relativos a cruzamentos dialélicos de variedades. 1970. 59p. Tese (Livre Docência) - Escola Superior de Agricultura Luiz de Queiroz, Piracicaba.

Recebido em 19 de março de 2011 e aprovado em 29 de abril de 2011 